\title{
Professional and peer support preferences for women who self-harm in custody
}

\begin{abstract}
Research question

To explore the support preferences of women who self-harm in prison from the perspectives of women themselves, prison staff, and prison Listeners.

Purpose

Peer and professional support are important for women in prison to help them tackle a range of issues including self-harm. To date, research has not explored in any depth how women experience peer support provided in prison to help them manage their self-harm including peer support provided through the Listeners Scheme.
\end{abstract}

\section{Design/methodology/approach}

This was a case study in one women's prison employing mixed, qualitative methods. These included a questionnaire distributed to women and staff, a focus group with prison Listeners, semi-structured interviews with women who self-harmed and semi-structured interviews with prison staff, together with a series of observations in the prison site.

\section{Findings}

While women in prison welcomed both professional and peer support their support preferences were influenced by how serious women considered their self-harm to be and the degree to which they regarded their relationships with staff as trusting and/or supportive. The therapeutic community that operated in the prison facilitated different relationships between women who self-harmed in prison and staff, than have hitherto been reported in the research literature. These relationships described by women and staff as 'more open' allowed women to seek staff support when managing their self-harm behaviours. Women sought peer support from Listeners in addition to staff support particularly at times when staff were unavailable for example at evenings and weekends.

\section{Research limitations/implications}

The case study design was conducted in one women's prison which operated a therapeutic community (TC). The principles of the TC that operated in the prison are supported by the wider literature on Therapeutic Communities as conducive to good mental health. Findings are thus relevant for establishments with TCs .

\section{Originality/value}

Women opted for support from staff for helping them to manage their severe self-harm, over and above the peer support available through the prison Listener scheme. This finding contrasts with previous research that suggests women trying to manage their self-harm in prison prioritise 
support from their peers because staff are often found to harbour unhelpful attitudes to women's self-harm that makes seeking support difficult.

Key words - Prison Listener, women prisoners, self-harm, prison peer support, prison staff, Therapeutic Community

\section{Article Classification - Research paper}

\section{Introduction}

The 3,797 women in prison in the UK are in the minority compared to their 78,675 male counterparts (Official Statistics, 2019). However women's self-harm in prison remains a concern for the authorities because women in prison engage in approximately 4 times more incidents of self-harm than men and current rates of self-harm in women in prison have increased by $24 \%$ from the previous year (Ministry of Justice, 2018). Self-harm can be defined in different ways, although within prison and health services in the UK, it is generally defined as any "act of selfpoisoning or self-injury carried out by an individual irrespective of motivation" (National Institute for Health and Care Excellence (NICE), 2011, p. 4).Challenges remain regarding how to provide support and interventions to manage this behaviour in a current prison climate of reduced resources, which is reflected in the lower numbers of prison staff, staff with less experience of working in the prison system and limited funding for mental health care (National Offender Management Service (NOMS), 2016).

Research has repeatedly demonstrated that self-harm in prison is a gendered issue that can be attributed to women's experiences prior to prison (Wright et al, 2017) and/or their attempts to cope with the prison environment (Caulfield, 2016). Policy makers and researchers agree that women experience prison in gender-specific ways (Walker \& Towl, 2016, Crewe., et al 2017), affected by; prior experience of abuse (Wright et al., 2017, Prison Reform Trust, 2017), restricted access to children (Corston, 2007, Baldwin, O'Malley \& Galway, 2015), mental health issues (Light et al., 2013), and the removal of existing coping methods even when these are problematic; such as using drugs and/or alcohol (Prison Reform Trust, 2017). Being imprisoned intensifies women's vulnerabilities which renders them at a greater risk of self-harm than before they entered custody (Caulfield, 2016).

Though the gendered needs of women who self-harm in prison have increasingly been recognised, more work is required to ensure that the prison estate provides appropriate support to help women manage such behaviour. This is especially important since when women selfharm in prison, these behaviours are often engaged in more frequently or are more life threatening than in the community (Ward \& Bailey, 2012).

The National Offender Management Service stipulates that peer support should be provided to all prisoners in England and Wales (NOMS, 2012) and the prison estate offers a range of peer support provision typically with the aim of providing advice and guidance for a variety of practical and emotional concerns (HM Inspectorate of Prisons, 2016). Prisoners are also encouraged to engage in providing peer support themselves as a means of earning enhanced incentives and privileged status (NOMS, 2013). Peer support schemes are complementary to the 
professional support already provided by prison staff, and should not undermine professional relationships between staff and prisoners (NOMS, 2012).

One such peer support scheme, and the longest running, is the Listener Scheme. Historically, the Listener Scheme was introduced as a form of prison peer support in the 1980s within male prisons such as HMP Swansea and is a model based upon and fully supported by Samaritans. Whilst the aim of the Listener Scheme is not to reduce self-harm per se it operates with the same purpose of preventing suicide as the main Samaritans service. Listeners are trained by the Samaritans to provide a confidential listening service with the intention of alleviating emotional distress and preventing suicidal thoughts/behaviours (Scowcroft, Winder, Oldfield and Slade, 2018).

Research in men's prisons demonstrates positive benefits of the Listener Scheme for those who use it and the peer supporters (Scowcroft, Winder, Oldfield and Slade, 2018). However little is known about how the scheme is experienced in women's prisons (Davies, 1994). Indeed Griffiths \& Bailey (2015) conducted a systematic literature review to explore the contribution of the Listener Scheme as a source of support for women who self-harm in prison and conclude that there is a need for further research as studies are typically small scale, and lacking objectivity.

In some prisons, Therapeutic Communities (TCs) have been introduced in a move to re-orientate prison culture to balance therapy as well as custody (Brookes, 2010, Morris, 2004), with prisoners' working and living together, and contributing to the therapeutic milieu (Garelick, 2000). Some reported benefits of TCs are prisoners' engagement in a range of group therapeutic activities, sharing of information within less hierarchical structures and the assessment and resolution of concerns within the group setting (Brookes, 2010). Given the potential difference in prisoner-staff relationships afforded by a TC, the experience of peer support schemes within women's prisons that operate a TC has yet to be fully explored.

This study aimed to explore women's experiences of using the Listener Scheme as a dedicated offer of peer support to help them manage their self-harm in one women's prison that operated such a therapeutic community.

Research site

Several women's prisons that were known to provide a Listener Scheme, as the only condition for inclusion, were approached to take part in the study. The prison selected as the research site housed approximately 280 women on seven wings, with women's sentences ranging from a few months to thirty-two years. At the time of data collection, the prison employed approximately seventy-one Uniformed Officers, twenty supervising officers and nine Custodial Managers. All seven wings were single cell accommodation with one exception, which had ten cells that each woman shared with one other. Each wing adopted a different function some typical of prisons generally while the TC was located within a separate wing of the prison and enabled women to work on changing their behaviour concerning their initial offence by accessing group therapy sessions, which involved the whole community once a week and smaller group therapy sessions which took place three times a week. If a woman or a fellow TC member had a particular concern, this was raised in the therapy sessions and this enabled the women to work through the issue together, within a supportive environment. This process allowed the women to 
develop healthy relationships with others, with the intention of similar relationships being cultivated when women were released from the prison estate.

\section{Methods}

The research utilised a case study design (Stake 2005) and employed mixed methods as appropriate to this approach as advocated by Yin (2013). A positivist stance was adopted by including a questionnaire to gather quantitative data on the uptake of the Listener Scheme. This was combined with an Interpretivist approach with qualitative data captured from semistructured interviews, a focus group and observations to explore how the scheme was experienced by women who self-harm in prison, staff and the Listeners themselves.

At the time of the research the Listener Scheme represented an under-researched contribution to the forms of support available to help women manage their self-harm in prison. Important questions related to how the Listener Scheme was being experienced and why this might be so; for example because of women's gendered experiences of self-harm prior to and during imprisonment (Crewe et al 2017). These how and why questions Yin (2013) argues aligns well with the case study approach.

The case study design employed a two-stage approach to the recruitment of participants and collection of data.

Stage 1 -methods

Methods in stage 1 included a questionnaire distributed to women, and a separate, albeit similar questionnaire distributed to all prison staff including wing officers and staff groups within the prison for example Chaplaincy, Psychology, Education etc. The questionnaire aimed to elicit information about why women engaged in self-harm in prison and why they might seek support from the prison Listener Scheme to help them when trying to manage this behaviour. The questionnaire for the staff explored their views about the contribution of the Listener Scheme as a source of peer support to help women to manage their self-harm in prison. Responses to open ended questions relating to women's and staff's knowledge and experiences of the Listener Scheme as a form of peer support for self-harm, influenced the purposive selection of women and staff to take part in semi-structured, in-depth, interviews.

Listeners were not asked to complete a questionnaire during Stage 1 of the study as this was a condition of NOMS ethical approval. Instead all Listeners were invited to take part in a focus group in Stage 1.

Ethical clearance for the research study was obtained from The National Offender Management Service (NOMS) and from the hosting University.

Stage 2- methods 
A recurrent category from the interviews and the focus group was that women prioritised professional support for self-harm above peer support from the Listener Scheme. This preference appeared to be influenced by how the TC operated in the prison so observations were conducted on prison wings as well as on the TC to explore this and theorise further. Observations were conducted with the knowledge and written consent of staff and prisoners who were asked a series of open-ended follow up questions to check for understanding of the observed interactions. Following the observations, the researcher shared the notes of the observations with the women and staff members who confirmed that the observations were a true reflection of their experience.

Figure 1: Participant samples and methods

\section{Stage 1}

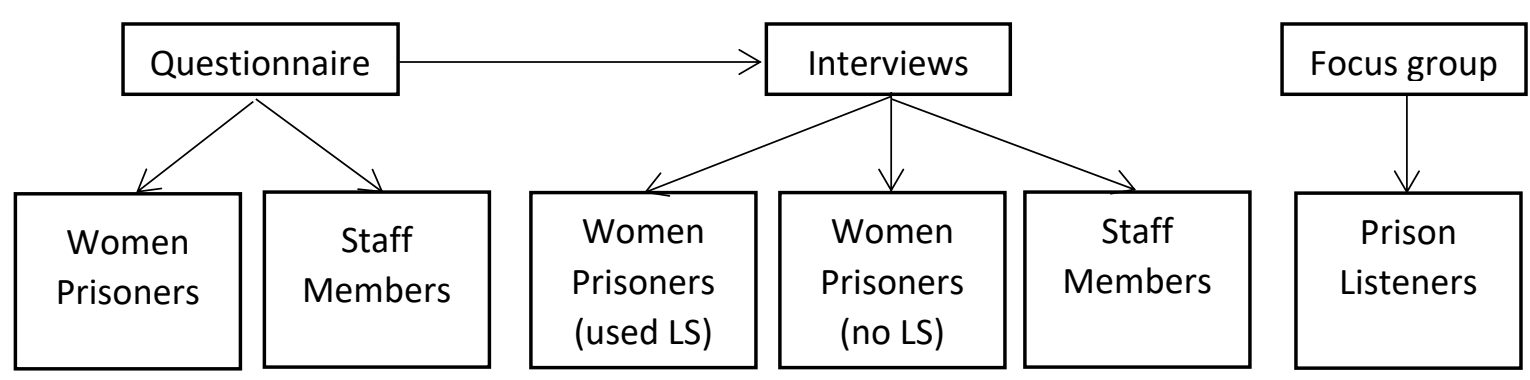

Stage 2

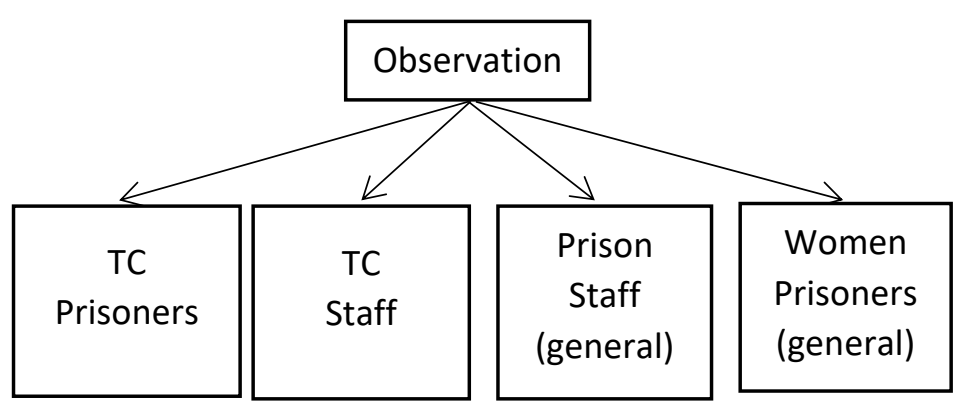


SAMPLING - Interviews and focus groups

Table 1 shows the numbers and demographic mix of the staff, women and Prison Listeners who were sampled to take part in the research. The study included a mix of male and female staff and participants reflected a range of ethnicities and age groups. Two Samaritan volunteers were present during the focus group as requested by the Listeners, although the Samaritan volunteers did not contribute to the discussion. Two of the Listeners declined the invitation to be part of the study.

Table 1: Participant sample

\begin{tabular}{|c|c|c|c|}
\hline Participants & $\begin{array}{l}\text { Questionnaires } \\
\text { Completed }\end{array}$ & Semi-structured interviews & $\begin{array}{l}\text { Focus } \\
\text { Group }\end{array}$ \\
\hline $\begin{array}{l}\text { Women in } \\
\text { custody who } \\
\text { self-harm }\end{array}$ & 30 & $\begin{array}{l}10 \text { who used the Listener Scheme } \\
10 \text { who did not use the Listener Scheme }\end{array}$ & \\
\hline Prison Officers & 45 & 2 & \\
\hline $\begin{array}{l}\text { Safer Custody } \\
\text { Officers }\end{array}$ & 5 & 2 & \\
\hline Samaritans & 2 & & 2 \\
\hline Psychology & 5 & 1 & \\
\hline Chaplaincy & 2 & 2 & \\
\hline Healthcare & 3 & 1 & \\
\hline $\begin{array}{l}\text { Rehabilitation } \\
\text { Addicted } \\
\text { Prisoners Trust } \\
\text { (RAPT) Staff }\end{array}$ & 2 & 1 & \\
\hline $\begin{array}{l}\text { Psychologically } \\
\text { Informed } \\
\text { Planned } \\
\text { Environment } \\
\text { (PIPE) staff }\end{array}$ & 1 & 1 & \\
\hline Prison Listeners & & & 8 \\
\hline Total & 95 & 30 & 10 \\
\hline
\end{tabular}


Table 2 shows which type of sampling was used with which method and participant for stage one and two of the data collection.

Table 2: Participant sampling strategies

\begin{tabular}{|l|l|l|l|}
\hline Data collection & Method & Participant & Sampling \\
\hline 1 & Questionnaire & Prisoners & Opportunity \\
\hline 1 & Questionnaire & Staff & Random \\
\hline 1 & Interviews & Prisoners & Purposive \\
\hline 1 & Interviews & Staff & Purposive \\
\hline 1 & Focus group & Listeners & Purposive \\
\hline 2 & & Prisoners & Theoretical \\
\hline 2 & Observations & Staff & Theoretical \\
\hline
\end{tabular}

Sampling approaches were tailored to meet the requirements for NOMS ethical approval. Opportunistic sampling was employed for the questionnaire. Information sheets, consent forms and questionnaires were given to two staff members in the Safer Custody Department of the prison. These staff members approached women who previously and/or currently engaged in self-harm in prison. The women were given time to read the information sheet, and to decide if they wished to participate then the staff member would provide the consent form and the questionnaire. The women gave the consent form and questionnaire back to one of these two staff members once these were completed.

Purposive sampling was employed to select the women and staff for interview based on their responses to the questionnaire. Women were selected who reported that they had used the 
Listener Scheme to help them manage their self-harm in prison and the same number of women were selected who had similar experiences of self-harm but had not chosen to use the Listener Scheme, or declared no knowledge of its existence.

Members of prison staff were purposively selected based on a reported prior knowledge and experience of how the Listener Scheme supported women to manage their self-harm in prison. Staff were selected to reflect wing officers and discipline specific staff. The sample size for staff taking part in the interviews was informed by the pragmatics of getting busy staff released for any length of time without impacting significantly on the smooth running of the prison regime.

Table 3: shows the participants observed for the second stage of the data collection.

Table 3: Observation participant sample

\begin{tabular}{|l|l|}
\hline Observations & N \\
\hline Therapeutic Community (TC) prisoners & 20 \\
\hline Therapeutic Community (TC) staff members & 9 \\
\hline Prisoners on general wings & 20 \\
\hline Staff general wings & 4 \\
\hline Staff safer custody & 4 \\
\hline Total & $\mathbf{5 7}$ \\
\hline
\end{tabular}

During the observation stage one prisoner declined to participate in the study. Observations on the TC included women's group therapy meetings, staff meetings and Safer Custody meetings. Safer Custody officers had a designated role in offering support to women who self-harm in prison for example through the Assessment Care and Custody Teamwork (ACCT) process. Four days were spent observing in the prison environment with two of these days spent in the TC.

\section{Data Collection Tools}

The questionnaires, interviews, and focus group guides were developed from conducting reviews of the existing literature and were intended to explore the impact of the prison environment on women's self-harm, coping mechanisms and support preferences. Observation guides were informed by the categories emerging from all the above methods.

\section{Data Collection}

During the interviews which lasted on average for 60 minutes, the women were asked questions to explore the reasons why they engaged in self-harm behaviours and who they contacted to support them to manage this. In the focus group Prison Listeners were asked to discuss their experiences of providing support to women in prison and how this related to self-harm behaviours in particular. 
The interviews and the focus group were followed by a series of observations that allowed us to theorize about how the contribution of the Listener Scheme was influenced by staff support to help women manage their self-harm in prison.

During the course of the interviews with women who self-harmed and the staff members, a number of categories emerged from the data. As these categories re-occurred, it became evident that they needed further investigation. Moreover, constructivist grounded theory supports the flexibility of the methods employed, which enabled subsequent investigations of emerging categories from within the data (Charmaz, 2014). 
Figure 2: Methods and stages of data collection 


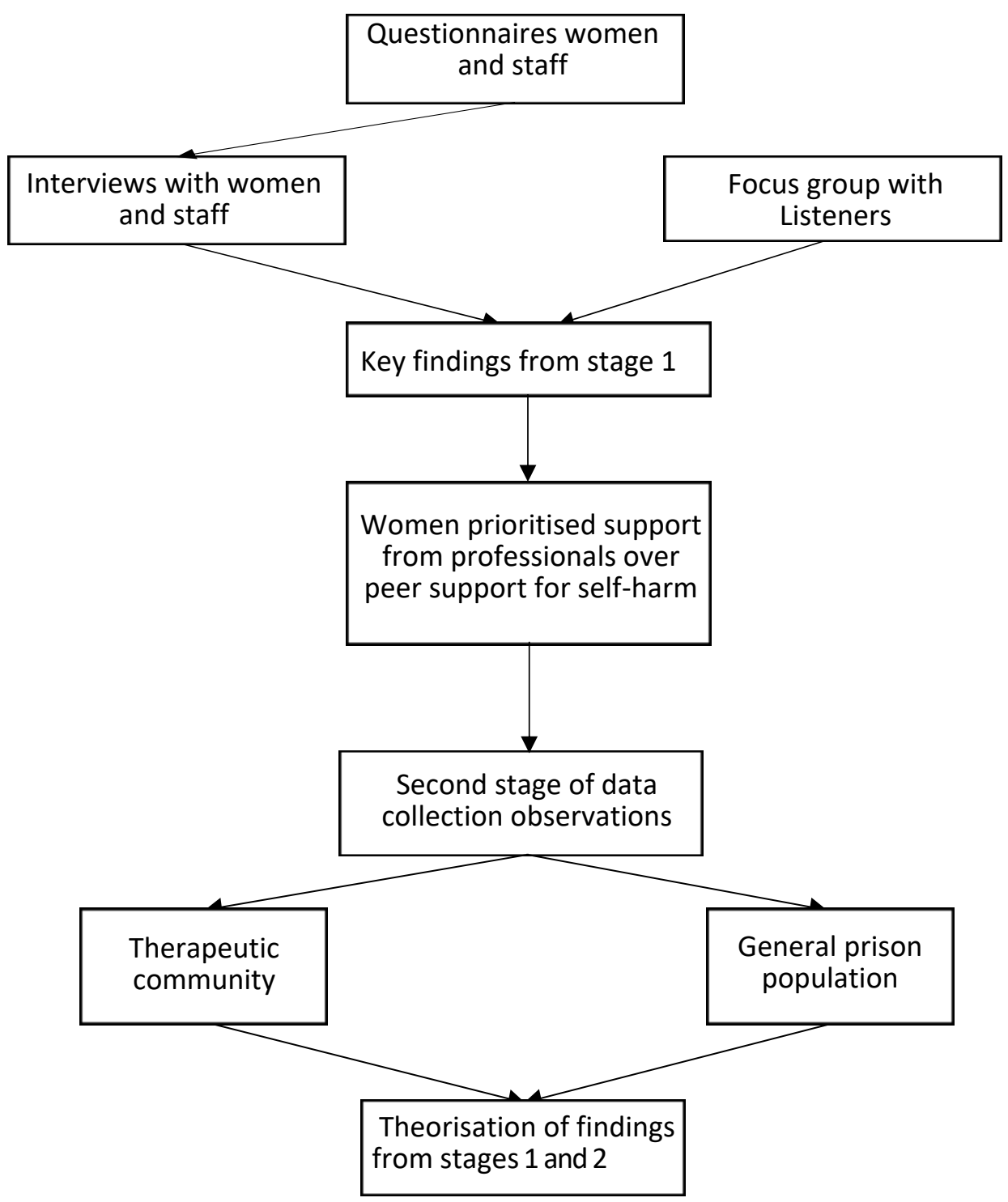

Data Analysis

In accordance with Her Majesty's Prisons security protocols and as stipulated by the research site at the time of data collection, an audio recording device was not permitted in the prison. Consequently, detailed notes were taken for all the interviews, focus groups and observations. These notes were written up into transcripts as soon as possible after the data collection occurred to preserve the quality of the verbatim data for analysis and to allow for any salient non-verbal communication to be documented, for example tone, silence, length of pauses during the interview (Charmaz, 2014). Pseudonyms were assigned to preserve the anonymity of women who were interviewed. 
Data from the interviews, focus groups and observations were analysed employing a bottom up, inductive, grounded theory approach, using line by line coding in the first instance (Charmaz, 2014) followed by focus coding to consider the context of the line- by- line codes. This approach allowed for categories to emerge from the data.

The data was collected and coded initially by a single researcher. Emerging categories were confirmed by another senior research at the University and in discussion with the Listeners at the research site. 


\section{Results}

Women's preferences for support reportedly depended on the severity of their self-harm and timing of need; and were considered to be influenced by the TC that operated in the prison. The preference for professional over peer support was documented in the whole prison, which was found to be influenced by the operation of the TC.

Figure 3 Relationship between professional and peer support

Figure 3 illustrates the influence the TC has on the prison environment, which results in the women prisoners developing trusting relationships with staff members. This trusting relationship supports the women to seek support from the staff members for their selfharm, when their behaviour is seen as too severe ('past it' )for peer support.

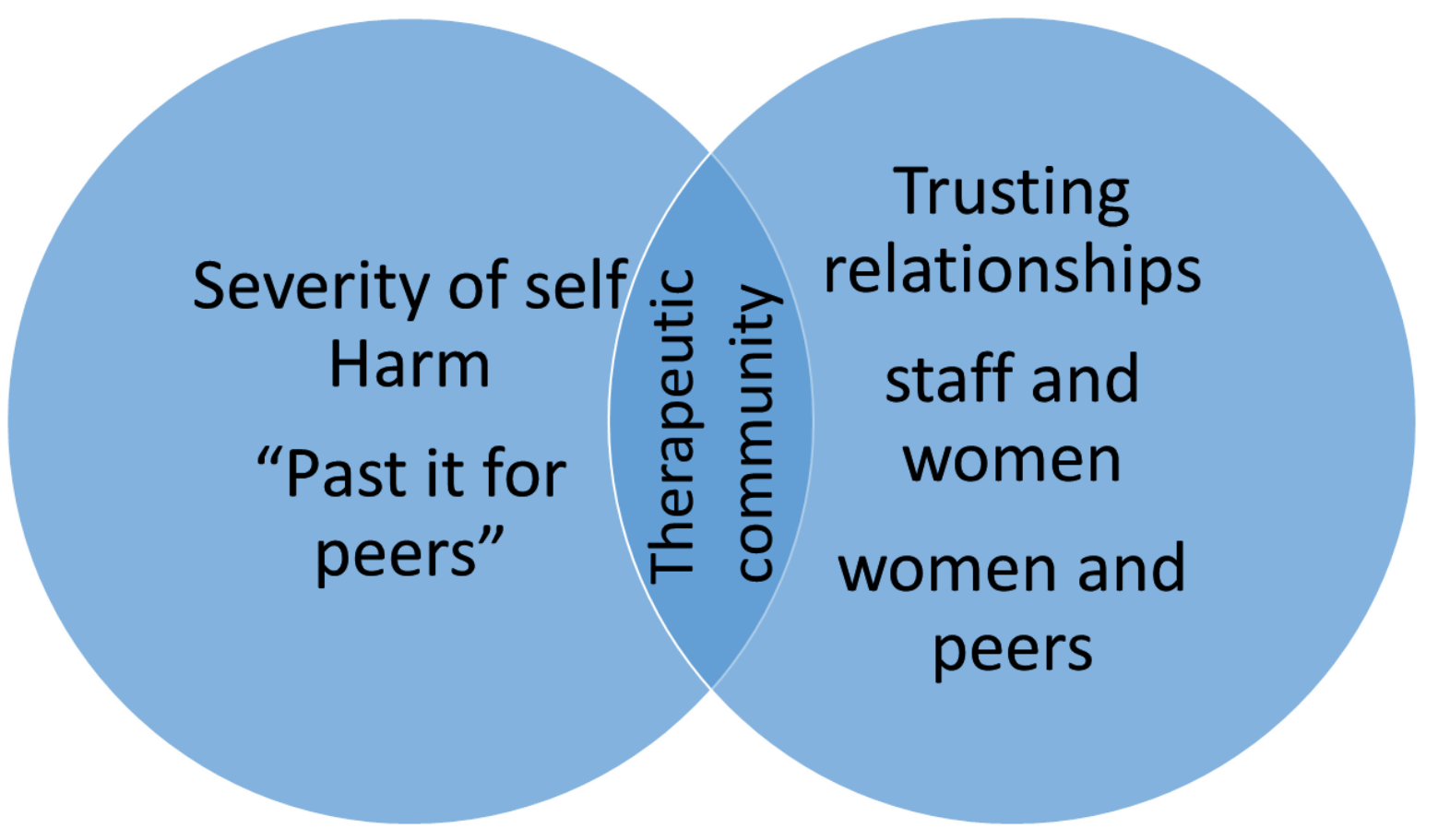

An overarching category emerging was that when women considered that their self-harm was serious they preference was to seek a professional response because in their words their self- harm had gone 'Past it for peers"' (Ann Prisoner TC interview).

For some women support from staff members in a professional capacity was seen as the only option as explained by Norma "I used to see Listeners, I need more help as my selfharm is getting bad....this time I know if I do this next time I know I will be dead. Mental health in reach, I go there once a week, it's helped a lot. If I hadn't seen a mental health professional I wouldn't be here today" (Norma, prisoner interview).

The importance of professional support was echoed by the Listeners, 
"They [the women] know what they are doing, no level of support will make them stop. We're not there to make them stop. Professional help is about underlying issues, they have to make the decision to seek help" (Gemma, Listener focus group).

The severity of women's self-harm was also evident in observations of group therapy sessions taking place on the TC.

Paula explains 'Peer support is all well and good, but not for me now (there is a long pause as she looks off in to the distance), I'm well past that, I need staff, my self-harm is bad bad bad' (Paula, prisoner TC interview).

Prisoners, and staff acknowledged that Listeners can only listen and that whilst this is important there is also a requirement for professional advice and the stimulation of a different thought process, as one staff member explained, "Needs to be a multi-disciplinary approach where professionals are involved. We want to keep the prisoner safe. Need to process, listening is great but processing can be a journey" (Ian, staff member interview main prison).

The focus on 'just' listening was echoed by the Listeners "Always stated we aren't equipped with mental health, accept people where they are at the moment. We signpost, just listening" (Ruth, Listener focus group).

Keeping women who self-harmed safe in prison was a key concern, staff and women articulated that one reason why staff support was sought over that from the Listeners was because staff could open Assessment Care in Custody and Teamwork (ACCT) documents and signpost to the relevant support whether from Safer Custody or the mental health in-reach team, as Norma explains,

"If it got really bad I would go and speak with Safer Custody, then the Listener Scheme if staff are busy" (Norma, prisoner interview).

To illustrate further a woman is observed in the main prison stopping a staff member in the corridor. The woman explains she has received some bad news from her Social Worker recently which had led to a 'Bad night' in relation to her self-harm behaviour. The staff member agrees to return to allow the woman to discuss her feelings towards the news from the Social Worker (Observation, main prison). This observation demonstrates a responsive approach from the staff member which in turn fosters trust.

Such examples of staff members building trust with the women reportedly influenced why women sought their support rather than support from the Listeners. Merry explains this preference "I have used more staff than Listeners, staff have been really supportive" (Merry, prisoner interview).

Concerns about Listeners keeping women's self-harm confidential was given as another reason why women would trust staff to approach for support rather than listeners "For selfharm they (prisoners) will come to staff, more confident to go to staff, they don't want their peers to know." (Gary, staff member main prison). 
The supportive nature of the TC encouraged women to manage their need to engage in self-harm behaviours by verbalising their emotions. A group therapy session on the TC is observed when women share details of their crimes with staff members who acknowledge women's individual characteristics and behavioural responses. One woman is accused of drug taking on the TC. Women and staff explore the allegations and the reasons why the woman had allegedly resorted to this behaviour, to arrive at an agreed response. Throughout the session open communication between the women and staff on the TC is demonstrated which reportedly influences the trusting relationship women build with staff and which enables the women to seek staff support to help them to manage their self harm behaviour. As Joy explains "TC has helped stop my self-harm. I no longer need a scar to show I'm hurting inside, I can talk about it now in group" (Joy, prisoner, TC interview).

Despite staff being busy the women reported that staff were accessible and this was highly valued "Staff are excellent you can always talk to them" (Laura, prisoner interview). On one occasion this was observed on the TC when staff members delayed their team meeting to talk to a prisoner who had recently been struggling with her self-harm behaviour, this accessibility is explained by a Listener,

"There are officers no matter how busy they are will dedicate time to you. Safer Custody come back to you." (Polly, Listener focus group).

\section{Professional and peer support: extensions of each other}

Despite women's reported preference for staff support, staff themselves acknowledged the real value of the Listener scheme at times when they were not available; "We as staff are in a position of power, we get to leave, even carrying keys. Evening and weekends would be risky without peer support" (Ian, staff member). Peer support also helped staff to manage demanding workloads "It (Listener Scheme) is the most valuable scheme in the prison service, it does save lives and helps staff cut our workload significantly" (Gary, staff member, interview main prison).

The Listeners concurred that their contribution was particularly important on those occasions when staff time was limited; "Even if you have a general query staff don't have that quality one on one time, you rely on your peers for support in that way it helps. It works well. (Katie, Listener focus group).

Laura explains how a removed hierarchy on the TC allows for professional and peer support to become extensions of each other;

"TC is really good support. On TC you have professional support every day and can buddy in the evenings" (Laura, prisoner, observation)

Observations on the TC revealed that staff used a non-judgemental approach with the women, which included spending more time with them and being on first name terms. The group therapy session ends and staff members have a cup of tea and a chat with the women in the socialisation area of the TC. During these discussions, the staff and women use each 
other's first names and talk about what films they had watched at the weekend

(Observation, TC). The observation reveals that staff use informal approaches to ensure that the women are ok after the therapy session has ended and contributes to a "removed hierarchy" between staff and prisoners.

Staff and prisoners' likened women's experiences in prison that often triggered self-harm to that of being a castaway on a desert island where time stands still, yet the prisoner continues to think about their life that they left behind on entering prison. Life outside prison continues and changes at a quicker pace than prisoners' can often comprehend when they are released. The TC reportedly creates an 'island' in prison which because of its reduced size and increased numbers of staff members, enables prisoners to form attachments with staff and fellow prisoners. These enabling relationships reportedly act to support women to manage their self-harm in prison thus lessening their dependency on the bespoke peer intervention provided by the Listeners. The Listener Scheme is seemingly experienced as an off 'island' (TC) source of peer support for women who self-harm, available during the evenings and weekends when there is less staff presence (Griffiths, Bailey and Slade in preparation).

\section{Discussion}

This study sought to understand how peer and professional support are important for women in prison to help them tackle a range of issues including self-harm. This study documented a preference for professional over peer support across the whole prison and theorised how professional and peer support may operate as extensions of each other. Women prioritised professional support for self-harm above peer support (Listener Scheme) when this is provided within a prison site that operates a Therapeutic Community.

The women in this research (on and off the TC) prioritised the support they received from staff to help them manage their self-harm when serious; preferring to use dedicated peer support in the form of the Listener Scheme during times of restricted staff availability. This is a surprising finding given that previous research has been critical of staff support, drawing attention to staff's negative attitudes to women's repeat self-harm and staff being poorly prepared to offer supportive interventions for such behaviour (Marzano et al, 2012). In this study staff support was reportedly preferred by the women because it was offered in the context of the trusting relationships staff were able to build with the women, a finding in contrast with Liebling's previous research (2007). These trusting relationships were particularly influenced by the presence of a TC on one of the prison wings.

While previous research has debated the usefulness of the Listener Scheme in general (Snow, 2002) and the barriers to its successful operation when staff don't support it (Foster and Magee, 2011) the findings in this study suggest the opposite, with staff and Listeners providing support as extensions of each other to offer different types of support to that women in prison can access to help them manage their self-harm at different times across the prison regime. 
The TC provided an environment in the prison where these sources of support could co-exist as extensions of each other and could be considered as contributing to what Covington, (2007) describes as a less punitive prison environment which balances custody and care.

The case study design employed in this study allowed for the combination of qualitative research methods to elicit detailed rich description and understanding of how staff and peer support co-exist to enable women to manage their self-harm behaviours in prison. By focusing the observations in stage 2 on areas of the prison that allowed a key category emerging from stage 1 to be further contextualised it is possible that some areas of further exploration were overlooked. Stake (2005) highlights this tension between the case and the categories that emerge. While the case study method was limited to one women's prison the operation of the Therapeutic Community as conducive to improved mental health experiences for those in prison is reflected in the wider research literature on TCs more generally.

The body of evidence exploring peer support in prison, is sparse, and although the Listener Scheme is more widely used than most other forms of prisoner peer support, further research is needed to measure the benefits it affords and highlight best practice (Woodall et al., 2015).

\section{Conclusion}

This study explored the support preferences of women who self-harm in prison from the perspectives of women themselves, prison staff, and prison Listeners. The key findings show that women prefer to access support for their self-harm from professionals over peer support (Listener Scheme) across the whole prison when provided in a prison which has a TC. The findings of the current research contribute to this under-researched area, importantly highlighting the role a prison TC can play in fostering a conducive environment where staff and peer support can become extensions of each other.

Indeed, whilst a key finding suggests that some women are 'past it for peers' in relation to their self-harm behaviour and support requirements, this study shows there is an important role for professionals and peers to fully support women who self-harm in custody. Thus, this study suggests professionals and peer supporters should work together as extensions of each other.

\section{Recommendations}

1) Examine how prisons might implement aspects of the TC ethos in order to improve staffprisoner relationships

2) Explore relationships between staff and Listeners to understand how they can work together more effectively for women at different stages of their self-harm behaviour 
3) Investigate the impact of different types of peer support on self-harm related outcomes in prisons Future research

- Longitudinal research to investigate different types of peer support and whether these sources of support result in better outcomes in prison (de-escalation of conflict, violence, self-harm) and on release

\section{Reference list}

Bagnall, A, M. et al. (2015). A systematic review of the effectiveness and cost-effectiveness of peer education and peer support in prisons. BMC Public Health, 15: 290.

Baldwin, L., O'Malley, S., and Galway, K. (2015). Addicted mothers. In Baldwin, L. (2015), Mothering justice: working with mothers in criminal and social care settings. Waterside Press.

Brookes, M. (2010). Putting principles into practice: The therapeutic community regime at HMP Grendon and its relationship with the 'Good Lives' model. In Shuker, R., and Sullivan, E. (2010), Grendon and the emergence of forensic therapeutic. Wiley-Blackwell.

Caulfield, L. S. (2016). Counterintuitive findings from a qualitative study of mental health in English women's prisons. International Journal of Prisoner Health, 12(4): 216-229.

Charmaz, K. (2014). Constructing Grounded Theory: second edition. London: Sage.

Corston, J. (2007). The Corston Report. Ministry of Justice. London: HMSO

Covington, S., and Bloom, B. E. (2007). Gender responsive treatment and services in correctional settings. Woman and Therapy, 29, (3-4): 9-33.

Crewe, B., Hulley, S., and Wright, S. (2017). The Gendered Pains of Life Imprisonment. British Journal of Criminology, p.azw088.

Davies, B., (1994). The Swansea Listener scheme: views from the prison landings. The Howard Journal, 33(2): 125-35.

DeVilly, G. J. et al. (2005). Prison-based peer-education schemes. Aggression and Violent Behavior, 10 (2): 219-40.

Farrant, F., and Levenson, J. (2002). Barred citizens: volunteering and active citizenship by prisoners. London: Prison Reform Trust.

Foster, J., and Magee, H. (2011). Peer support in prison healthcare: an investigation in to the listening scheme in one adult male prison. Project report, School of Health \& Social Care, University of Greenwich, Greenwich and London.

Garelick, T., (2000). Therapeutic Communities. Past, Present and Future: Edited by Penelope Campling \& Roy Haigh. The British Journal of Psychiatry, 176(3), pp.304a-304. 
Griffiths, L., and Bailey, D. (2015). Learning from peer support schemes - can prison Listeners support offenders who self-injure in custody? International Journal of Prisoner Health, 11(3): 157-168.

HM Inspectorate of Prisons (2016). Life in prison: Peer support. Available online:

https://www.justiceinspectorates.gov.uk/hmiprisons/wpcontent/uploads/sites/4/2016/01/Peer-support-findings-paper-final-draft.pdf. Accessed 25th November 2018

Jaffe, M. (2012). Peer support and seeking help in prison: a study of the Listener Scheme in four prisons in England. Available online: www.repository.keele.ac.uk. Accessed $7^{\text {th }}$ June 2018.

Liebling, A. et al. (2005). Revisiting prison suicide: the role of fairness and distress. The Effects of Imprisonment, pp. 209-231. Cullompton: Willan Publishing.

Liebling, A. (2007). Prison suicide and its prevention. In Jewkes, Y. (ed.), Handbook on Prisons, 243-446. Willan Publishing, Devon.

Light, M. et al. (2013). Gender differences in substance misuse and mental health amongst prisoners. London: Ministry of Justice. Available online:

https://assets.publishing.service.gov.uk/government/uploads/system/uploads/attachment data/file/220060/gender-substance-misuse-mental-health-prisoners.pdf Accessed 17th December 2018.

Macdonald, M., Sexton, S, and Barr, P. (2002). Self-harm and Suicide Policy Implementation in West Midlands Prisons. Centre for Research into Quality, University of Central England, Birmingham.

Marzano, L., Ciclitira, K., and Adler, J. (2012). The impact of prison staff responses on selfharming behaviours: prisoners' perspectives. British Journal of Clinical Psychology, 51(1): 418.

Ministry of Justice (2018). Safety in Custody Statistics, England and Wales: Deaths in Prison Custody to December 2017 Assaults and Self-harm to September 2017. Available online: https://assets.publishing.service.gov.uk/government/uploads/system/uploads/attachment data/file/676144/safety-in-custody-q3-2017.pdf . Accessed 7 June 2018.

Morris, M. (2004). Dangerous and Severe: Process, Programme and Person: Grandson's Work. London: Jessica Kingsley.

National Institute for Health and Clinical Excellence (2011). Self-harm: longer-term management CG133. National Institute for Health and Clinical Excellence, Manchester. Available online: https://www.nice.org.uk/guidance/cg133/resources/selfharm-in-over-8slongterm-management- pdf-35109508689349. Accessed $7^{\text {th }}$ June 2018.

National Offender Management Service (NOMS) (2012). A distinct approach: a guide to working with women offenders. Available online:

https://www.justice.gov.uk/downloads/publications/noms/2012/guide-working-withwomen-offenders.pdf. Accessed $7^{\text {th }}$ June 2018.

National Offender Management Service (NOMS) (2013). Women's Custodial Estate Review. Available online: 
https://www.gov.uk/government/uploads/system/uploads/attachment data/file/252851/ womens- custodial-estate-review.pdf. Accessed $7^{\text {th }}$ June 2018.

National Offender Management Service (NOMS) (2016). Annual report and accounts 201516. London: HM Stationery Office. Available online:

https://www.gov.uk/government/uploads/system/uploads/attachment data/file/535810/N OMS AR 2015-16 FINAL WEB 2 .pdf. Accessed $7^{\text {th }}$ June 2018.

Official Statistics (2019). Prison populations statistics. Available online:

https://www.gov.uk/government/statistics/prison-population-figures-2019 Accessed 28th January 2019

Prison Reform Trust (2017). Why focus on reducing women's imprisonment? Available online:

http://www.prisonreformtrust.org.uk/Portals/0/Documents/Women/whywomen.pdf Accessed $17^{\text {th }}$ December 2018

Snow, L. (2002). The role of formalised peer-group support in prisons. In G. Towl, L. Snow and M. McHugh (2002), Suicide in Prisons. Oxford: Blackwell

Stake, R. E. (1995). The Art of Case Study Research. Sage.

Syed, F., and Blanchette, K. (2000a). Results of an Evaluation of the Peer Support Program at Grand Valley Institution for Women, Correctional Service of Canada.

Tate, T., and Copas, R. (2010). 'Peer Pressure' and the Group Process: Building Cultures of Concern. Reclaiming Children and Youth, 19(1): 12-16.

Walker, T., and Towl, G. (2016). Preventing self-injury and suicide in women's prisons. Waterside Press.

Ward, J., and Bailey, D. (2012). Consent, confidentiality and the ethics of PAR in the context of prison research. In Love, K. (ed.) (2012), Ethics in Social Research, pp. 149-173. Bingley: Emerald publishing.

Woodall, J. et al . (2015). Expert views of peer-based interventions for prisoner health. International Journal of Prisoner Health, 11(2): 87-97.

Wright, S., Crewe, B., and Hulley, S. (2017). Suppression, denial, sublimation: Defending against the initial pains of very long life sentences. Theoretical Criminology, 21(2): 225-246. Yin, R. K. (2013). Case study research: design and methods, 5th edition. Sage Publications. 
